\title{
The Treatment of Depression in Primary Care
}

\author{
A Cross-sectional Epidemiological Study \\ by Dr. rer. nat. Sebastian Trautman, Prof. Dr. rer. nat. habil. and Katja Beesdo-Baum, et al. in issue 43/2017
}

\section{Limitations of the Study}

In our opinion, the study (1) has substantial limitations/ shortcomings - but these were not mentioned in the text. This makes it almost impossible to interpret the results.

- The data came from only $5.8 \%$ of the physicians who had been contacted-consequently they are anything but representative.

- The Depression Screening Questionnaire (DSQ) was developed for the purpose of screening; it cannot be used to make a clinical diagnosis. This means that a substantial proportion of patients whose test results were positive do not actually have depression - as is made clear by the low specificity of the test (2). Furthermore, the test reflects only what happens in those few weeks that the questions relate to. This makes it impossible to make a diagnosis of depression, as in some cases it is only situation-specific low mood that is being measured (3).

- Defining a mean value that includes patients with suspected mild to moderate depression, is misleading, especially as far as assessing the quality of treatment is concerned. Medication treatment for mild, even moderate, depression is explicitly stated to be not sufficiently evidence-based in the current version of the national disease management guideline (4), which also applied at the time when the study was conducted. The same is true for international guidelines.

Apart from the-flawed-study, it deserves to be said that the treatment of the depressive patients (who had been identified by the GPs themselves, without using any questionnaire) seemed very good indeed. Therapy rates in severe, moderate, and mild depression were $97 \%, 87.5 \%$, and $79.1 \%$. To infer inadequate treatment from such results and to deduce from that the need to "improve general practitioners' ability to diagnose these conditions and determine the indication for treatment" is unsupportable. Rather, it shows the authors' biases.

DOI: 10.3238/arztebl.2018.0133a

\section{References}

1. Trautmann S, Beesdo-Baum K, Knappe S, et al.: The treatment of depression in primary care-a cross-sectional epidemiological study. Dtsch Arztebl Int 2017; 114: 721-8.

2. Becker N, Abholz H-H: Prävalenz und Erkennen von depressiven Störungen in deutschen Allgemeinarztpraxen - eine systematische Literaturübersicht. Zeitschr Allg Med 2005; 81: 474-81.

3. Sielk M, Altiner A, Janssen B,et al.: Prävalenz und Diagnostik depressiver Störungen in der Allgemeinpraxis - ein kritischer Vergleich zwischen PHQ-D und hausärztlicher Einschätzung. Psychiat Praxis 2009; 36:169-74.
4. DGPPN, BÄK, KBV, AWMF (eds.) für die Leitliniengruppe Unipolare Depression: S3-Leitlinie/Nationale VersorgungsLeitlinie Unipolare Depression - Langfassung, $2^{\text {nd }}$ edition. Version 5. 2015. www.depress ion.versorgungsleitlinien.de (last accessed on 30 January 2018).

Prof. Dr. med. Heinz-Harald Abholz (Emeritus) Institut für Allgemeinmedizin, Universität Düsseldorf

Dr. med. Günther Egidi

Abteilung Allgemeinmedizin, Universität Göttingen

Prof. Dr. med. Michael M. Kochen, MPH, FRCGP (Emeritus)

Abteilung Allgemeinmedizin, Universität Göttingen

Lehrbereich Allgemeinmedizin, Universität Freiburg

\section{Dr. med. Uwe Popert}

Abteilung Allgemeinmedizin, Universität Göttingen

uwe.popert@web.de

\section{Conflict of interest statement}

The authors declare that no conflict of interest exists.

\section{Incomplete and Curtailed Statements}

Trautmann, Beesdo-Baum, and coauthors on the basis of their cross-sectional study postulate inadequate treatment of patients with depressive disorders and conclude from this a need to "improve general practitioners' ability to diagnose these conditions and determine the indication for treatment" (1). In their original article they refer repeatedly to the national disease management guideline for unipolar depression as the basis of their argument (2). Central statements of this guideline are, however, reproduced in the article in abbreviated and incomplete form.

According to the guideline, relatives should be included in planning the treatment, and the principles of shared decision making should be adhered to. Among others, medical decision aids should be used. For this study it would therefore have been necessary to collect data on the use of such decision aids and on the conclusions that patients arrived at as a result of using these.

We may assume that thanks to evidence-based decision aids, patients have realistic expectations of the chances of success for diverse specific interventions and will make highly differentiated therapeutic decisions. According to the guideline, for example, the response rate for antidepressants is usually $50-60 \%$ and the response rate for placebo $25-35 \%$.

Only in full awareness of these data should authors focus on undertreatment/inadequate treatment and the need for relevant further professional training/education. New insights should also be considered. At least one therapeutic study of antidepressants overestimated 
the effects of medication therapy and underestimated the harms (suicide and extended suicide [3]), owing to manipulations (4).

DOI: $10.3238 /$ arztebl.2018.0133b

\section{References}

1. Trautmann S, Beesdo-Baum K, Knappe S, et al.: The treatment of depression in primary care-a cross-sectional epidemiological study. Dtsch Arztebl Int 2017; 114: 721-8.

2. DGPPN, BÄK, KBV, AWMF (eds.) für die Leitliniengruppe Unipolare Depression: S3-Leitlinie/Nationale VersorgungsLeitlinie Unipolare Depression - Langfassung, 2. Edition. Version 5. 2015. www.depression. versorgungsleitlinien.de (last accessed on 30 January 2018). ).

3. Arzneimittelkommission der deutschen Ärzteschaft: SSRI und Suizidalität? Bekanntgabe 2004. www.akdae.de/Arzneimittelsicherheit/Bekannt gaben/Archiv/2004/200409242.html (ast accessed on 12 January 2017).

4. Doshi P: No correction, no retraction, no apology, no comment: paroxetine trial reanalysis raises questions about institutional responsibility. BMJ 2015; 351: h4629.

\section{Dr. med. Armin Mainz}

Korbach

dialog@praxis-korbach.de

\section{Conflict of interest statement}

Dr Mainz is an unpaid volunteer in the supervisory board of the arriba cooperative, whose services include decision aids for depressive patients.

\section{In Reply:}

We thank our colleagues for their comments. Here are our responses to the issues raised.

Representativeness: Low participation rates in primary care studies are a fundamental problem, which brings with it uncertainty regarding selection bias (1). Beyond speculation, there is no option for establishing unequivocally whether non-participations really introduce substantial biases into the assertions. In view of the large heterogeneous sample of doctors, it seems unlikely that such biases need to be assumed. Greater participation in publicly funded studies of independent and interdisciplinary research groups is undoubtedly desirable but seems unrealistic in spite of enormous efforts.

Diagnostic screening: In view of the enormous amount of time it takes to establish a state-of-the-art a clinical diagnosis of depression confirmed by a differential diagnostic evaluation, we depend in primary care on screening methods with possibly poorer specificity. We used the Depression Screening Questionnaire (DSQ), a diagnostic screening instrument with satisfactory reliability as well as acceptable sensitivity and specificity in comparison to the gold standard that is the diagnostic interview (2). The symptoms of a depressive episode that we collected in this way correspond to the length of time that is required according to established criteria to make a diagnosis of a depressive episode (two weeks). The persistence is reflected too ("on most days"). It is therefore correct that a formal clinical diagnosis is not possible on the basis of the DSQ, but a depressive syndrome can be ascertained, and this can be differentiated from, for example, transient situational low mood.

Severity: The reported results are consistently differentiated by severity. Even the mean value that our correspondents mentioned incorporates-especially considering the quality of treatment- the results according to the degree of severity. Furthermore, reasons are given for why in this cross-sectional study, pharmacological treatment is categorized as evidence-based even in mild depression, in contrast to the guideline recommendation. On the one hand, patients who were previously affected by moderate to severe depression may currently be at least in partial remission, thanks to psychopharmaceutical treatment. On the other hand, what should not be dismissed out of hand is that the availability of outpatient psychotherapy may be limited or that a patient decides against this treatment option. This has been described and is a phenomenon that doctors encounter in real-life clinical practice.

Undertreatment: We related and discussed undertreatment only in the setting of specific subgroups (patients whose condition remained undetected) and specific treatment components (such as lacking indications of guideline-conform combination treatment in severe depression, psychotherapy in sustained mild depression). All in all, we agree with the interpretation that treatment rates in patients with depression diagnosed by doctors are positive. It is justifiable to point out that the treatment is complex: for example, according to the national disease management guideline for unipolar depression, the patient and his/her relatives should be included when planning the treatment, and principles of shared decision making should be considered (3).

The presentation of such complex matters reaches limitations in a single research article, and it was not possible to include all available data in detail. Further analyses are needed and possible in order to shed light on the multitude of reasons that serve as obstacles to the use of the recommended therapies according to the guideline (4).

DOI: 10.3238/arztebl.2018.0134

\section{References}

1. Güthlin C, Beyer M, Erler A, et al.: Rekrutierung von Hausarztpraxen für Forschungsprojekte. Erfahrungen aus fünf allgemeinmedizinischen Studien. ZFA 2012; 88: 173-81.

2. Beesdo-Baum K, Knappe S, Einsle F, et al.: Wie häufig werden $\mathrm{Pa}$ tienten mit depressiven Störungen in der hausärztlichen Praxis erkannt? Bundesgesundheitsblatt - Gesundheitsforschung - Gesundheitsschutz 2018; 61: 52-64

3. Trautmann S, Beesdo-Baum K, Knappe S, et al.: The treatment of depression in primary care-a cross-sectional epidemiological study. Dtsch Arztebl Int 2017; 114: 721-8.

4. Mack S, Jacobi F, Gerschler A, et al.: Self-reported utilization of mental health services in the adult German population-evidence for unmet needs? Results of the DEGS1-MentalHealthModule (DEGS1-MH). Int J Methods Psychiatr Res 2014; 23: 289-303.

On behalf of the authors

Prof. Dr. rer. nat. habil. Katja Beesdo-Baum

Technische Universität Dresden, Institut für Klinische Psychologie und Psychotherapie

Behaviorale Epidemiologie \& Center for Clinical

Epidemiology and Longitudinal Studies

Katja.Beesdo-Baum@tu-dresden.de

Conflict of interest statement

The author declares that no conflict of interest exists. 